\title{
Sonic mediatization of the book: affordances of the audiobook
}

\section{Iben Have and Birgitte Stougaard Pedersen}

MedieKultur 2013, 54, 123-140

Published by SMID | Society of Media researchers In Denmark | www.smid.dk The online version of this text can be found open access at www.mediekultur.dk

This article addresses cultural changes resulting from the growing number of audiobook users and changes in audiobook use emerging from digital technological developments of the past decade. The sonification of the written text is inscribed in the general transformation and mediatization of the printed book but offers radically different affordances than do visually perceived e-books. New portable digital audio media change the act of reading, moving it towards fields of practice in which reading has not been common before: the gym, the bicycle ride, gardening, resting in the dark, etc. From being a medium typically associated with children, the visually handicapped, or the dyslexic, the audiobook has developed into a popular phenomenon, which, we argue, has as much in common with other kinds of mediated mobile listening practices, like music and radio listening, as it has with the reading of printed books. Taking an inductive approach from the micro-level of the individual's use, the term affordances will be used as a methodological tool within the concept of mediatization.

\section{Introduction}

Media and communication studies have often sketched out the history of the book, mainly within the tradition of medium theory, in which the mass production of text is emphasised as the decisive factor in the change from a media matrix characterised by orality (where 
words were spoken and listened to) to a matrix dominated by printed words and visual reading (McLuhan, 1964; Eisenstein, 1979; Ong, 1982; Meyrowitz, 1985; Finnemann; 2005 etc.). McLuhan describes this development as a cultural transformation from an acoustic to a visual space of perception, with a communicative separation in time and space (McLuhan, 2006 [1964]). Today, we find ourselves on the threshold of new digitised formats for books, with e-readers like iPads and Kindles slowly but steadily taking the place of the paper book.' This entails considerations of how the mediatization of the book may challenge knowledge and learning, consumption and experience (Ludes, 2008; Baron, 2012).

An overlooked aspect of the history of the mediatization of the book is the history of the audiobook, in particular the digital renaissance of this medium over the past few years, during which period new portable delivery technologies and distribution channels have radically expanded both its use and its user groups. In Denmark, audiobook unit sales increased by more than 100 pct. from 2009 to 2010 (Bogbarometret 2011, p. 25), and Publizon, which is the biggest provider of digital audiobooks on the Danish market, announced a similar increase from 2011 to 2012 and anticipates equivalent growth in 2013 (Andersen 2013). The Danish libraries are experiencing a growing interest in audiobooks as well. Since 2009, between 50,000 and 60,000 new audiobooks have been acquired by Danish libraries every year (Nielsen, 2012). American publishers too are heralding the success of the audiobook and noting that audiobooks, rather than e-books, represented the main revenue source among non-traditional, non-print products in 2012 (Thompson, 2010, pp. 351-352).

It is problematic to differentiate between a-books (audiobooks) and e-books (electronic books) even though it is common to do so since audiobooks are electronic books and, moreover, turned books electronic and digital long before tablet technology. Instead, the audiobook constitutes a sub-category of the main category, the e-book. An audiobook is typically defined as a recording of a text read aloud by the author, a professional narrator, or a synthetic voice. Edison's invention of the phonograph in 1877 returned the book to the oral tradition of the spoken word, though characterised by a communicative separation in time and space (cf. Walter J. Ong's concept of secondary orality (1982)). Like the printed book, the audiobook is a one-to-many medium, distributing standardised content to an anonymous audience; at the same time, however, it is a new, highly individualised and mobile medium, adapted to individual needs and uses and with interactive possibilities still latent.

Some new formats, however, already combine the audiobook with interactivity and physical user involvement. One example is the Zombies, Run! application for iPhone, iPod Touch, Android, and Windows Phone (Six to Start, 2012), which is a hybrid between an interactive computer game and an audiobook in which an author has written a story that is read aloud while you try to optimise your exercise activities. The application's official webpage introduces it as follows: 
a trail, walking to work, or even running on treadmills. And if you want a serious workout, turn on thrilling zombie chases that force you to speed up to escape the hordes! (https:// www.zombiesrungame.com)

Zombies, Run! is an interesting example of how new user groups are drivers for pushing the audiobook towards new forms and an example of how the audiobook amalgamates with other digital media as well as non-media activities, such as running (Schulz 2004, p. 89). However, the empirical basis for this article's analysis is the classic audiobook, a recording of a written book (usually fiction) read aloud by a professional narrator and played on new mobile digital delivery technologies such as smart phones and iPods. We wish to analyse the audiobook as a technological, aesthetic/perceptual, and sociological medium and discuss some of the social and cultural changes that may result from the sonic mediatization of the book. ${ }^{2}$

The sonification of written text is inscribed in the general transformation and mediatization of the printed book over the last decade but offers radically different affordances than do visually embedded e-books. The new portable and digital audio media change the act of reading, moving it into fields of social practice such as exercising, commuting, and housekeeping in which reading has not previously been common. Alongside other media, the use of audiobooks represents part of the general mediatization of these fields. We take an inductive approach to the discussion of the transformative processes of mediatization, focusing on the experiential character of audiobooks, on reading-as-listening in the everyday life, and on the social practices of individuals. Through a case study like the audiobook, the often very abstract and all-inclusive concept of mediatization can be made more concrete, and its heuristic values and shortcomings become more apparent. Micro-scale observations may give rise to more general assumptions about how the use of audiobooks influences social and cultural practices on institutional levels as well. However, rather than drawing profound conclusions on the macro-level, our aim here is to highlight and investigate the audio component of the general mediatization of the book.

In the next section, we will briefly describe the technological development of the audiobook, peaking with its digital renaissance today. In the sections that follow, we consider some of the primary affordances of the audiobook as a kind of media logic, focusing on the affordances related to sound and listening and to the immateriality of the MP3 file. We extend the concept of affordance to include the voice and discuss it in relation to rhetorical intentionality. In the last section, we draw some conclusions on cultural change in accordance with these affordances of the audiobook, indicating some perspectives on the institutional level of society as well.

\section{The digital renaissance of the audiobook}

Relative to the development of the printed book, beginning with Gutenberg's invention of the printing press in 1455 , the development of the audiobook was a sidetrack to the general mediatization of the book, a sidetrack branching off when Edison invented the 
phonograph in 1877 . The phonograph was, in fact, originally invented for the purpose of recording speech, not music, which has been its primary use ever since. The technological development of the audiobook began with spoken-word recordings, ${ }^{3}$ which were supplied using the heavy reel-to-reel technique after the Second World War. The portable audio cassette developed during the 1970s, and the word audiobook was first introduced in that context (Rubery, 2011, p. 8). In the 1980s, the digital compact disc replaced the audio cassette, and in 2002, audiobooks became available for download (and later, streaming) from the Internet through compressed digital formats such as MP3. Though the compact disc is still an important player in the market, audiobook readers in recent years have moved away from physical CDs to more convenient computerised sources. This development can be observed for both books and music. The hardware of the audiobook has over the years become more flexible and more mobile: To use Rubery's example, while an unabridged recording of Tolstoy's War and Peace once required 119 records, 45 cassettes, or 50 compact discs (Rubery, 2011, p. 9), today's MP3 file has made the audiobook weightless and not limited to one delivery technology.

As noted by Rubery, editor of the only academic book on audiobooks so far, it is significant that the audiobook as a medium has more in common with recorded music than it does with printed books. Audiobooks nearly always use platforms designed for music, which makes the consumption of such devices in the last decade pivotal to their success. But audiobook reception and use also have much in common with radio, and of course with talk radio in particular, which has itself undergone a digital transformation. Today, music, radio, and audiobooks all converge in individualised, computerised delivery technologies like smartphones and iPods and amalgamate with the everyday activities of private and social life (Schulz 2004, p 89).

An American survey from 2006, undertaken by the Audio Publishers Association, showed that audiobook users are becoming younger and better off. In 2006, the typical American audiobook reader was defined like this:

\footnotetext{
Younger listeners, split evenly between male and female, who live in slightly larger households (many with children) and command a higher income than has been reported in previous surveys. Audiobook listeners also have more education and buy and read more printed books than non-listeners (Audiobook Market Survey, 2006, p. 1).
}

Historically, audiobooks were associated with children or with users who were visually handicapped or dyslexic. But new and expanding user groups have recently driven the audiobook into new areas and towards new user groups where reading has not usually been practiced. For example, half of audiobook buyers are men, who, in contrast, buy only one in four printed paper books - a pattern applicable to audiobook loans from Danish libraries as well (Arvin, 2010). We have experienced that the use of audiobooks has become widespread in gyms in Denmark, and truck drivers represent another new user group that has caught our attention. Since 2004, truckers in Denmark have been able to borrow audio- 
books from the so-called trucker library in Padborg, with the (in Danish) rhyming slogan, Kør og hør - lydbøger til langturschauffører ('Drive and listen: audiobooks for truckers'). Padborg is a border crossing situated between Germany and Denmark, with 4,200 trucks passing through daily, and the trucker library has been a huge success (Nielsen, 2012). We visited the small library, which is administrated from an International Diesel Service Centre, and conducted an interview with the initiator of the project, librarian Maike Albertsen Zwoch. She told us that many of the truckers experienced an interest in literature for the first time in their lives since most of them do not read printed fiction (Zwoch, February 2013, see also Nielsen 2012). The most popular genre is crime fiction and autobiographies, but there has also been demand for language courses (Zwoch, 2013).

While the e-book is similar to the printed book in that you read with your eyes, word by word, the audiobook is so different from the printed book that it can be questioned whether it makes sense to call it a book at all. We have elsewhere analysed similarities and differences in the mediacies (Brügger, 2002) of the printed book and the audiobook (Pedersen \& Have, 2012). Our argument is that we should not discuss the audiobook merely as a re-mediation of the printed book but as an entirely different medium, one that should be conceptualised in relation to mobile media listening practices - as a part of the iPod culture, as described by Michael Bull (2007). We also need to discuss expanding the concept of reading so that it is no longer an act defined by vision. In colloquial language, we use the word reading in relation to braille: You do not touch braille, you read it. But for some reason, it is more natural to say, "I listen to an audiobook" than "I read an audiobook," perhaps because music delivery technologies are shared and received in a similar manner as is (talk) radio (on the everyday reception of radio, see Larsen, 1999).

The digital renaissance of the audiobook and oral narration emerging from growing popularity and new user groups call for new consideration of and investigation into the phenomenon. Research on audiobooks has been very sparse, however, and as a popular phenomenon, the field is almost unexplored.

\section{From logic to affordances}

Mediatization theory emanates from early medium theory, which basically addressed how changes in media matrices transform people's minds, social relations, and society (Meyrowitz, 1994; McLuhan, 2006). ${ }^{4}$ Medium theory has been accused of being too general and deterministic, yet Joshua Meyrowitz's definition of the main interest within medium theory is an example of how micro-analysis is also very present in this tradition (see also Lundby, 2009, p. 3), though usually from a deductive perspective:

Broadly speaking, medium theorists ask: What are the relatively fixed features of each means of communicating and how do these features make the medium physically, psychologically, and socially different from other media and from F2F interaction? (Meyrowitz, 1997, p. 50) 
This is essentially the same question we ask in relation to the audiobook, addressing, however, not only how the audiobook differs from the printed or tablet book but also its similarities with other kinds of mobile audio media.

Both mediatization theory and medium theory distinguish between two social levels. In medium theory, a differentiation is made between the macro cultural level, investigating how a new medium in an existing matrix of media alters culture and society in general, and a micro individual situation level, asking what effect the single medium has on the specific situation and social interaction (Meyrowitz, 1993, p. 51). Why, for example, do we choose to e-mail people rather than phone them? Why do we choose to listen to audiobooks instead of reading them visually?

Both micro-levels and macro-levels are present in current mediatization theory and are described as the two grand, interdependent claims of mediatization theory (Livingstone, 2009). Historically, however, mediatisation theory has focused mostly on meta-processes, discussing social and cultural changes related to media in a very broad sense comparable with other meta-concepts such as globalisation, individualisation, and commercialisation. From this meta-perspective, interest rests on the transformation of power relations between institutions and publics (Livingstone 2009; Lundby, 2009). But within the field of mediatization theory, there has been increasing demand for a greater connection to empirical analysis (Hjarvard, 2008 with reference to Krotz, 2007), bringing the phenomenon down both to the level of concrete everyday practices and processes and to the level of explorations of actual media forms (Drotner, 2008, p. 71). It seems inescapable, as Krotz and Hjarvard acknowledge, that only through knowledge of how people use the media can we study the meta-processes.

We are interested in the mediatization processes because we believe that the audiobook has cultural influence on how we read and experience literature in new social situations. The audiobook is, furthermore, an important player in the general digital mediatisation of the book over recent years, which publishers and libraries must take into account. But instead of adopting a coherent theory of mediatisation or a pre-existing theoretical framework for this analysis, we use a selective approach, combining the general idea of mediatization with the basic assumptions of medium theory and the concept of affordances to analyse audiobook use and experience from technological, aesthetic, and sociological perspectives.

Media logic is a key term within - and has been described as a driver behind - the processes of mediatization (Lundby, 2009, p. 7). Finnemann even defines the term media logic as an earlier term for mediatization, therefore almost as a synonymous concept (Finnemann, 2011, p. 67). Finnemann is very critical, claiming that the many processes involved cannot be unified into one concept and that terms like media logic and mediatization do not fit the study of mobile, digital media culture. The term was originally introduced by Altheide and Snow, who define it as "how material is organised, the style in which it is presented, the focus or emphasis on particular characteristics of behaviour, and the grammar of media communication" (referenced in Lundby, 2009, p. 8). Though this definition suggests a plu- 
rality of media logics, leading mediatization researchers like Hjarvard, Schrott, Strömbäck, and Esser often prefer to use it in the singular as a unified meta-concept (Lundby, 2009). We agree with Lundby, who argues that "the use of 'media logic' as an overall term weakens the scholarly argumentation about mediatization. Such a general concept hides the differentiation that people will know about" (Lundby, 2009, p. 105). From the individual's perspective, which includes different kinds of practices, habits, cognitions, and emotions situated very close to the sensing and perceiving subject, it simply does not make sense to inscribe the audiobook into one single media logic, which etymologically involves rationality and strict accordance with applicable rules. We find it more fruitful to use the psychological term affordance to specify mediatisation as a theoretical and analytical tool for describing the characteristics of the audiobook and how these afford cultural and social change.

The American psychologist J.J. Gibson introduced the term affordance in 1977 and developed it further in his 1979 book, The Ecological Approach to Visual Perception. With some similarities to Altheide and Snow's aforementioned definition of media logic, Gibson defined an affordance as a quality of an object that allows an individual to perform an action, as all "action possibilities" latent in an object. Gibsonian affordance can thus be analysed independently of an actor's ability to perceive the object. Our understanding of affordance is more in line with that used by Donald Norman, who defines affordance as a relationship between the object and the individual using the object, as a phenomenon of both actual and perceived properties emerging in the combination of the two (Norman, 1988). Both Gibson and Norman understand the term as related to the selection mechanism of the sensory apparatus. They define it in relation to vision, but it can be used for sound as well. Though a fleeting and non-material sound object is less easily grasped and defined than a visual object, it does afford perception and (re)cognition. The affordance of the digital audiobook is both the delivery technology, like an iPhone or MP3 files (its actual properties or its hardware and software), and the perceived suggestion as to how the technology should be used and the content experienced (its perceived properties). The narrating voice of the audiobook is, as we will see later, situated between these two categories. The advantage of Norman's concept is that, unlike the more deterministic and rationalistic associations of the term logic, affordance defines a quality that belongs neither to the medium nor to the user but appears in interaction between the two. Technological artefacts are social as well as technical and do not merely determine agency but also constitute it: perception, cognition, feelings, and habits (DeNora, 2000, p. 40). Even though affordances are usually used in the Gibsonian sense to capture the formal and objective characteristics (the logic) of a given medium, resulting from its constitution as a physical artefact, we find it necessary to emphasise the more subjective aspects of experience and use since our communicative material takes the form of ephemeral digital sound rather than of visual objects.

When it comes to a micro-scale study like the present one, it makes more sense to use the more dynamic and, in our sense, context-specific term affordances in the plural rather 
than the more static media logic in the singular. Affordance has been used in relation to mediatization theory before (Hjarvard, 2008, p. 39, and very briefly mentioned by Lundby, 2009, p.114; see also Helles, 2010), but to avoid the problematic aspects of using the term logic, we would like to take the relationship between the two concepts a step further by suggesting that, by studying the affordances of a specific medium, one also studies the micro-logics of the medium.

The term affordance also inscribes possibilities of the media not yet actualised by users and producers. We have several examples of this in media history, for instance the realisation of the camera, the text messaging function, or the display of recorded sound as latent properties of the mobile phone. Some affordances of the audiobook have not yet been fully actualised by users and producers but may be actualised in future. One example is the use of background music and sound effects in audiobooks. While a possibility, this is uncommon in traditional audiobooks for adults. Websites also have the possibility of integrating sound, music, and sound effects, but this never became a widespread practice: People probably prefer to watch and control webpages without being interrupted or distracted by music (Graakjær \& Jessen, 2011). But as we are arguing here that audiobooks have more in common with other instances of mobile listening, like music and radio, than they do with printed books, it would certainly be possible for future audiobooks to become more dramatised and sound designed, as has long been a tradition in radio drama and audiobooks for children. A sound-designed audiobook could be said to re-negotiate the practices of audiovisual media like film, television, and computer games, investigating the specific role and meaning of sound and music in imagined narrative spaces, like the aforementioned Zombies, Run! application. Another possibility is the combining of audiobooks with visual e-books. On the American market, it is possible to buy new e-novels in different but paratactic editions combining visual reading with audio reading and including a hypertextual function to seek information about selected concepts on the Internet. Actually, since 2009, Amazon's Kindle has included a text-to-speech feature, whereby a synthetic voice reads the book aloud (Rubery 2011, p. 10).

In the following sections, we will describe the specific features of the audiobook that make it different from the printed book and visual reading. We will methodologically use and develop the concept of affordance in relation to the audiobook, which involves concrete hardware (iPhone, iPod, etc.), software (MP3 files, etc.), and immaterial sound waves, which themselves carry different kinds of sonic affordances, such as voice. We thus find it necessary to understand the affordances of the audiobook as an interplay between technology, sound, and the experience of sound. Being aware that we use the concept of affordances in an unconventional way, we believe that both sound and voice are formal and communicative characteristics of the audiobook and that both can be described as specific affordances of the audiobook mediating meaning and content. 


\section{Sound as affordance}

The most profound affordance of the audiobook is that communication takes place through sound. Like books read visually, audiobooks are perceived through time but are autonomously controlled by the narrator. This might be described as a kind of audiotization of the printed book (alongside the process of mediatization) since the book is adapting the logic of sound communication, transforming the text and the act of reading into a totally different experience.

Anthropologist Tim Ingold argues in a short but thought-provoking article that sound is neither mental nor material but is a phenomenon of experience, which should thus be compared to light rather than to vision, as is widespread in sound studies as well as in media and film studies. Sound is, Ingold claims, a medium of our perception, "For sound, I would argue, is not the object but the medium. It is what we hear in. Similarly, we do not see light but see in it" (Ingold 2007, p. 11). McLuhan seems to forward a similar point by saying that "The electric light is pure information. It is a medium without a message" (McLuhan 1964, 2006, p. 8). Compatible with Ingold's and McLuhan's statements, media researcher Henry Jenkins has defined recorded sound and not the delivery technology as a medium:

History teaches us that old media never die. And before you say, 'What about the eighttrack,' let's distinguish among media, genres and delivery technologies. Recorded sound is a medium. Radio drama is a genre. CDs, MP3 files and eight-track cassettes are delivery technologies. Genres and delivery technologies come and go, but media persist as layers within an ever more complicated information and entertainment system. (Jenkins, 2001, p. 93)

Arguing that light and (recorded) sound are media necessitates using the term medium too broadly - which would be confusing in an article on mediatization. But if sound and light are media of perception - what we perceive in - then they can be described as general affordances, without which reading (whether with the eyes or the ears) could not take place.

\section{Micro-materiality and the mobility of the MP3 file}

The transformation of a written text into audio has historically been described as a decline. In the mid-1990s, film professor Sarah Kozloff studied what had been written and published about audiobooks (mostly in American popular media, journals, and newspapers), and she concluded:

The commentary I have found primarily focuses on comparing the format (often unfavorably) with the experience of reading printed books. To many, listening to audio books is a debased or lazy way to read, with connotations of illiteracy (only pre-literate children listen to stories); passivity (real reading entails self-construction of the narrative voice); abandonment of control (real reading involves pausing, skimming and savoring); and lack of commitment (real readers sacrifice other activities for their books). These underlying prejudices 
are reinforced by the format's association with such 'lowbrow' offerings as business advice and self-help titles, as well as radical abridgments of revered novels. Audio books are both dismissed as a negligible fad, and feared as another potent threat to traditional literacy. (Kozloff, 1995, p 83)

However, the increasing mobility of the audiobook has brought about a change in these values, as portability has become ever more important in modern society. The complaints mentioned by Kozloff have been replaced by perceived advantages. Reading audiobooks is timesaving, as you can do other things while reading; it promotes activity, because eyes and body are free to move; it is mentally engaging; it is convenient, inexpensive, etc. Rather than comparing audiobooks with printed books, we wish to advance a position that regards audiobook reading as a special instance of mobile listening (comparable to music, radio, audio guides, or audio therapy) - as a popular phenomenon that is part of the digital, mobile audio culture in a mixed-media environment.

Mobility is an important affordance of the digital audiobook, and it is interrelated to another important affordance, the micro-file (usually the MP3 file), which has a key role in this transformation of the audiobook towards flexibility and mobility. Jonathan Sterne has made a thorough analysis of the MP3 file as a cultural artefact and defines MP3s as a container technology for recorded sound. On the basis of psychoacoustic analysis of the compressed technology, he argues that MP3s use psychoacoustic principles to get rid of the qualities of sound that the human ear is unable to hear anyway and that the technology therefore affords a certain kind of use:

MP3s are designed to be heard via headphones while outdoors, in a noisy dorm room, in an office with a loud computer fan, in the background as other activities are taking place and through low-fi and mid-fi computer speakers. They are meant for casual listening (Sterne, 2006, p. 835).

So, the technical sound quality of the MP3 file in itself as well as its mobility affords distracted listening, which allows other sensory input to contribute to the reading situation and experience. Even though audiobooks are communicated through sound, the experience provided is not solely sonic. The audiovisual audiobook experience involves a possibly moving body and visual field, acting independently of the reading situation. This constant spatiotemporal negotiation thus makes the audiobook experience extremely complex. Even though his book focuses on music listening, Michael Bull (2007) has demonstrated that the meanings actual iPod users attribute to mobile sound technology are quite variable and strongly dependent on actual use. In the case of audiobooks, the cognitive process by which one acquires story and plot is, in principle, identical to that involved in the reading of a printed book, but the imagined fictitious space is constantly challenged by sensorial inputs, by the real physical space through which one's eyes and body move. As Sterne puts it, "The MP3 is designed for promiscuity, which has been a long-term goal in the design of sound reproduction technologies" (Sterne, 2006, p. 836). 


\section{Voice as affordance and rhetorical intentionality}

In our discussion of the specific characteristics of the sonic affordances of the audiobook, we wish to analyse the audiobook experience as a rhetorical situation in terms of the character and act of the voice. Affordances can thus be broadly understood as rhetorically regulated in the sense that a given object or practice will point its intentionality towards a specific use. The voice in this sense can be discussed both as a kind of 'software' or an actual property of the audiobook and as a special instance of rhetorical intentionality or a perceived property of the audiobook.

The rhetorical approach has many points in common with the affordance approach in that it deals with a certain way of understanding a communicative act and how the communicative act is intended. There are, however, crucial distinctions to be made between the two rhetorical approaches to the audiobook that we wish to pursue. In its materiality, the voice is a physical software whereas the rhetorical intentionality of the narrator is more closely linked to content and cannot therefore be described and understood as an affordance as such. Every act of communication is rhetorical, meaning that the book as a medium is an artefact involving a rhetorical aim both on the level of the narrated content and through its materiality or mediacy. As always, the question of intentionality is crucial here as it (like affordances) concerns directedness towards creating a specific relationship. In the case of the audiobook, the rhetorical approach differs markedly from that of the tablet book. Reading a tablet book with the eyes is in many ways similar to the act of reading a printed book: It is an exclusive, possibly high-absorbency practice, monopolising much of one's attention. This applies, of course, primarily to the reading perception since the tactile characteristics of e-book as well as the user perspective in terms of interactivity differ from reading a paper book. The rhetorical situation of the audiobook can be characterised as a meeting between the narrator's performative act of reading the text aloud and the reception situation characterised by a huge number of distractions from surrounding stimuli dependent on the listener's specific reception situation-commuting, walking, cycling, exercising, etc. We have elsewhere described this as non-exclusive, lowerabsorbency occupation: something one can possibly do while engaged in other practices (Pedersen \& Have, 2012). The rhetorical situation, then, is on the one hand intensified in the act of a physical performance or dramatisation of the text but on the other hand momentary and distracted.

\section{Narration and voice}

The written text, whether fiction or non-fiction, contains some implicit intentional structures. The content, style, and structure of the text each possess and produce an inherent rhetorical intention, which is related to but not identical with affordance. In narratology, concerning in principle all forms of texts, intentionality involves how a story is being told. Classic narratology, at a minimum, identifies the voices of the text, the narrator, and the 
author. The voice is connected to both the source and the manner of narration. The theoretical paradigms linked to theories of enunciation and narratology ask: Who is speaking, from where, and to whom? The narration of the text can thus be described as a rhetorical function concerning indications of positions on a semantic level: how events are presented to us or how we are allowed to gain access to them, as expressed by Gerard Genette's term focalisation (Genette, 2004 [1972], p. 76). In an audiobook, this narration is met and possibly extended by a different rhetorical strategy since that which is narrated is mediated or performed by a narrator in a verbal physical performance. That something is 'told' and not just experienced through the inner ear affects the narrating situation: It underlines or intensifies the intentional act of the text. We do not regard this narrating perspective as a specific affordance since it cannot be said to be based on any materiality, but we do consider it to be an essential part of the experience of the audiobook. The listener is thus assigned the intonation, tempo, and phrasing of the narrator in a very concrete way. On the one hand, the audiobook experience appears 'time forced' and tentatively frozen in the sense that the reading activity is quite strictly tied up since the audiobook user cannot easily make shortcuts or speed up or slow down the reading according to his or her level of interest or concentration, as can readers of printed books. On the other hand, the intensification of the rhetorical approach caused by the narrating situation seems vivid in the concrete act of enunciation: The narration produces an intensification of the listening space. It would also be relevant to discuss the audiobook experience alongside a number of other corresponding interplays, for instance the confusion of the concrete and the imagined spaces. The relationship between narrated space and sensed space is to some extent confused by the sensorial and multimodal modes of the audiobook experience. This overall experience or flux affects the listening process - the story to which you are listening will be influenced by the nature of your body movements and your surroundings. But at the same time, the listening experience will become part of the listener's experience and construction of her or his environment. Seen in this light, the reading practice may change your sensation towards a possible social withdrawal and towards a more introverted (aesthetic) attention towards your surroundings.

The voice plays a crucial role in determining the affordances of the audiobook. The sonic experience of an audiobook always includes a voice, either a recorded human voice or a digital, synthetic voice. Recent theoretical discussions, such as those in the anthology VOICE: Vocal Aesthetics in Digital Arts and Media, deal with the role of voice and the impact of digital culture, which necessitate a new theoretical framing. Some of these discussions frame the voice through a number of ambivalences that have implications for the concept, for instance the tension between an embodied and a disembodied voice or the voice as a mediator between language and sound. Neumark states, "We could hear voice as a hinge, holding the sonorous and signifying together and apart - preventing them from collapsing into a unity" (Neumark, 2010, p. xx).

Historically, the voice was associated with authenticity, identification, and subjectivity. Such romantic ideas or conceptions of voice, which remain influential to modern concep- 
tions as well, emphasise the elements of autonomous subjectivity and connect the voice to presence. In its use of synthetic, radically disembodied voices, the audiobook seems to challenge this notion, whereas in other versions, it reproduces the idea of an authentic voice by letting the author read, thereby vitalising his or her text. An actor reading the text mediates between these two versions, producing an effect of authenticity through his or her voice. Neumark deals with this issue in her article 'Doing Things with Voices', discussing the recent status of voice in relation to authenticity and asking whether the voice in digital media culture is still haunted by the imaginations of the authentic self. Regarding authenticity as performative, Neumark (2010) responds that this is not necessarily the case because the voice can produce the effect of intimacy through vocal qualities and vocal performance: "We can hear an embodiment that the voice brings forth in the making - rather than expressing a preexisting, essential body" (Neumark, 2010, p. 114). In this sense, the audiobook can still, disembodied or not, produce the sense of presence - as an effect.

The voice in your ears produces effects of intimacy, as well as giving the user a sense of present social company. We assume that, for users, it is not just the literal experience but also a feeling of casual parasocial company (Horton and Wohl, 1997) and comfort that makes the audiobook attractive. As Stig Hjarvard writes, inspired by Simmel's concept of sociability, media are social technologies providing entertaining parasocial contact with other real or fictional people (Hjarvard, 2005, p. 22) in a very non-demanding way. This is applicable to audiobook reception as well. Referring to Schulz's (2004) four mediatisation processes (extension, substitution, amalgamation, and accommodation), audiobooks substitute and extend (in time and space) the face-to-face activity of listening to someone reading for you in public as well as in private.

In studying the concrete modes of the narrating voice of an audiobook, it is relevant to discuss how the voice performs: that is, to consider materiality or grain (Barthes, 1988), tone, ambitus, dialect, and diction; the use of glottal stops, style, and intensity; and tempo, pauses, and timing. When a physical, audible voice reads the text aloud, a number of stylistic choices are made concerning the text. The literary intonation is shaped in the sense that a number of decisions are thoroughly considered or conducted: accentuations, intensity, tempo, phrasing, and voice qualities become part of the listening situation. In this process, several choices are made, and standardisation or hermeneutic closure may be the result. All of these features, while not directly related to the semantics of the text, are still crucial to our overall rhetorical understanding of the text and can be said to be due to the hardware or the materiality of the voice itself. The mediacy of the voice contains an inherent formal physicality that is always communicating. Words can change in meaning through accentuation, and choice of tone and intensity can both draw in and repel the user by, for instance, overdoing the intentionality of the text. Even though we are unable to confirm this claim scientifically, we have discovered that the narrator's style is crucial to an audiobook's success, to the extent that many audiobook readers look for their favourite narrator before they look for their favourite author when searching for a new audiobook. The voice of the 
English actor Stephen Fry, for example, has achieved almost iconic status in part because of his readings of Harry Potter.

One might discuss the vocal reading mode as a special instance of the rhetorical use of voice. It can be stylistically overdone, in which case it will not succeed in drawing the listener into the diegetic world of the story. The vocal reading mode is also relevant to the question of genre perspective, which we will touch upon only briefly here. The audiobook affords certain genres because of the fleetingness of sound perception. Complex educational books, for example, are not suitable for audiobook format because of the difficulty involved in immediately capturing the meaning in a fixed tempo. In 2009, fiction represented $76 \mathrm{pct}$. of American audiobook sales, with non-fiction representing less than $25 \mathrm{pct}$. (Audio Publishers Association, 2009).

\begin{abstract}
You know, cookbooks don't work in audio except in rare cases; diet books don't work in audio ... And there are particular categories that can work extremely well in audio - memoirs, for example, books that have a personality-driven narrator. The commercial fiction, plot-driven fiction also works very well in audio. Literary fiction, intricate, more characterdriven fiction, does not work as well in audio because your mind just can't track, the narrative has sort of gone on and you're about to try to figure out what that sentence meant (Interview from Thompson, 2010, p. 351).
\end{abstract}

The genre perspective of the audiobook thus supports more frequent production and distribution of certain types of literature, which also affects the institutional aspect of mediatization.

\title{
Perspectives on cultural change
}

The way we read, experience, and use books in our daily practice and in interaction with our surroundings is undergoing significant change. These changes are not just related to reading on an interactive screen instead of reading on paper; they are more radical changes that emanate from reading with the ears instead of with the eyes - a semiotic transformation from visual to audio (with the narrating voice an important transformer) that calls for new premises for reading. New places and spaces for reading emerge, opened up by the affordances of mobile audio media - affordances related to sound perception as well as to delivery technology.

We have discussed the sonic mediatization of the book from an inductive perspective by investigating some of the main affordances of the audiobook. We find the concept of affordance more applicable than that of logic for an experiential, micro-level study. As a result of working with communication through sound, we have expanded the notion of affordances to include not only the 'hardware-based' aspects of media technologies but also sound as medium of perception, microfiles, flexibility, mobility, multisensority, and the voice as specific and interrelated affordances of the audiobook. These affordances lay the ground- 
work for a very different kind of use and experience than that of visually embedded books yet share characteristics and amalgamate with music and radio listening. As a result, books reach new users, spaces, and places and change understandings of reading and literature.

The audiobook can be said to cause cultural changes alongside the transformation of the interplay between private and public already documented in audio culture studies (Bull, 2007). Audiobooks and individualised mobile audio media in general do something to our presence in the social world, resulting in new ways of interacting with our surroundings - involving not only a possible social withdrawal from everyday life and communities but also another kind of intense and aesthetic attention towards these same surroundings. The physical and mental effect of a voice in your ears, telling you a story, affects not only your reading practice but also parts of your everyday experience in general.

In this article, we use the term mediatization as a framework for discussing social and cultural change associated with the audiobook from a micro-perspective, which has implications for institutional changes at the macro level as well. The affordances of the audiobook have implications for the relationship between the three main agents of audiobooks: The users who seek availability and ease of use at low cost, the copyright holders in search of profitable business models, and public libraries striving towards the freest availability of digitised culture and information content (Wingren, 2012). If, as we argue in this article, the practice of reading is changed by mediatization, the future development of institutions like publishers and libraries will be affected, as technological challenge and cultural change force them to rethink their strategies.

The digital mediatization - audio as well as visual - of the book fundamentally alters our way of perceiving and our way of reading. In order to adapt to this new situation, institutions such as libraries, private providers on the Internet, and publishers are being forced to change their marketing and production strategies - or, to use Schulz's term for this process, they need to accommodate the way the media operate (Schulz 2004).

The new use and user situations created by the digital audiobook challenge general ideas about what literature is, and the hegemonic negotiations between the literary public and opinion makers (such as critics and academics) may have to undergo some form of modification. In the longer term, this could challenge the balance of power between expert institutions and the public (for instance, the concept of the 'Artworld' as put forth by Arthur C. Danto). As 'literature' begins to be defined as a non-exclusive, low-absorbency occupation in addition to an exclusive, high-absorbency practice, a significant cultural change in values may occur. The structures concerning power and the structures controlling the market are not necessarily interrelated as the logics of power not seems to be particularly dependent on empirical patterns of reading. However, it is expected that the scholarly literary environment is moving into a field between literature and technology, needing to accommodate the development of new media. Literature will hereby coincide with other audio media and will, in this process, be integrated into everyday life and practices. 
The audiobook contributes to the mediatization of social practice in many spheres, whether these be reading, commuting, doing housework, gardening, exercising, truck driving, etc. This is a reciprocal process: For example, the increasing frequency of commuting and exercise in modern Western society in turn influences the development and use of the audiobook, as is evident in the case of Zombies, Run! As the relationships between users, libraries, and providers are undergoing rapid change, and further research is necessary, we are unable to describe the audiobook's long-term influence on reading culture. We can only point to a number of spheres or cultural reading practices where we expect it to have an influence as well as point to a change in cultural values as more and more people choose to listen instead of eye-read - and do so to words instead of to music.

\section{Notes}

1. August $7^{\text {th }} 2012$ Amazon UK announced that on that day the sale of e-book outnumbered the sale on printed books (Bay, 2012).

2. This article is an initial part of a longer study of the project The digital audiobook: A new medium, new cognitive experiences, new users? which will include empirical studies of different user groups. The project is financial supported by AU-Ideas Project Development.

3. Not many spoken word phonographs survive from before 1914. It was first in the 1930s recordings of novels in whole length begun in Britain and the United States (Rubery, 2011, p. 5).

4. The close relationship of mediatization theory and medium theory is also emphasised by Hjarvard 2008, Lundby 2009, Livingstone 2009 and Schulz 2004.

\section{References}

Altheide, D.L. \& Snow, R.P. (1991). Media Worlds in the Postjournalism Era. New York: Aldine de Gruyter.

Andersen, Katrine Jo (2013). Langt flere lytter til e-bøger, politiken.dk, 07.01 2013. Retrieved 9 January 2013 from http://politiken.dk/kultur/boger/ECE1861491/langt-flere-lytter-til-e-boeger/.

Arvin, Sanne (2010). Den digitale revolution er startet på lyd, Perspektiv: Bibliotekarforbundets Fagmagasin, 23.09 2010, Retrieved on 8 February 2013 from http://perspektiv.bf.dk/Bladet/2010/15/DenDigitaleRevolutionErStartetPaaLYd.

Audio Publishers Association (2006). Audiobook Market Survey: Customer Profile, Usage Patterns, and Experiences, Retrieved 7. February 2013 from http://www.audiopub.org/LinkedFiles/2006ConsumerSurvey COMPLETEFINAL.pdf.

Audio Publishers Association (2009). Audiobook Sales Increase in 2009. Retrieved 7. February 2013 from http://www.audiopub.org/PDFs/SalesSurveyPR62810.pdf.

Baron, Naomi (2012). The Impact of Digital Technologies (conference paper). The End of the Book? Maybe. Does It Matter? (public lecture). Mobile Communication. Mobile Internet, Locative media, Mobility and Place, Aarhus University, March 29-30, 2012.

Barthes, Roland (1988/1977). The grain of the voice. In: Image, Music, Text, The Noonday Press, New York. 
Bay, Morten (07-08-2012). 'Amazon sælger nu også flere e-bøger end fysiske bøger i Europa' Retrieved 7 February 2013 from http://politiken.dk/tjek/digitalt/internet/ECE1712368/amazon-saelger-nu-ogsaa-fleree-boeger-end-fysiske-boeger-i-europa/.

Bogbarometret. Lydbøger 2010, BogMarkedet 06, 2011, p. 25, Retrived 7 February 2013 from http://www. bogmarkedet.dk/sites/default/files/Statistik/Bogbarometer/Bogbarometer\%20Lydboger_2010.pdf.

Brügger, Niels (2002). Theoretical reflections on Media and media History. In: Brügger, N. \& Kolstrup, S. (Eds.), Media History: Theories, Methods, Analysis. Aarhus: Aarhus University Press.

Bull, Michael (2007). Sound Moves: iPod Culture and Urban Experience. New York: Routledge.

Couldry, Nick (2012). Media, Society, World, Cambridge: Polity Press.

DeNora, Tia (2000). Music in Everyday Life. Cambridge: Cambridge University Press.

Drotner, Kirsten (2008). Boundaries and Bridges: Digital storytelling in education studies and media studies. Lundby, K. (ed.). Digital Storytelling, Mediatized Stories. New York: Peter Lang.

Eisenstein, Elizabeth (Ed.). (1979). The printing press as an agent of change: communications and cultural transformations in early modern Europe, 2. vol. Cambridge UK: Cambridge University Press.

Finnemann, Niels Ole (2005). Internettet i mediehistorisk perspektiv, Copenhagen: Samfundslitteratur.

Finnemann, Niels Ole ((2011). Mediatization theory and digital media. Communications 36 (2011), pp 67-89.

Gibson, J.J. (1979). The Ecological Approach to Visual Perception. Boston: Houghton Mifflin. 1986).

Graakjær, N. \& Jessen I. (2011). 'De stille reklamer på nettet'. Retrieved May 172013 fom http://videnskab.dk/ blog/de-stille-reklamer-pa-nettet.

Have, I., Krogh, M., Larsen, C.R., Lønstrup, A., Nielsen S.K., Pedersen, B.S., Vandsø, A. (2010). Hear (h)ear - An acoustemological manifesto. Aarhus University.

Helles, Rasmus (2010). Personlige medier i hverdagslivet Ph.D.-dissertation. Copenhagen University.

Hjarvard, Stig (2005). Det selskabelige samfund. Copenhagen: Samfundslitteratur.

Hjarvard, Stig (2008). The Mediatization of Society. A theory of the Media as Agents of Social and Cultural Change. Nordicom Review 29 (2008) 2, pp 105-134.

Ingold, Tim (2007). Against Soundscape, Carlyle, A. (ed), Autumn Leaves: Sound and the Environment in Artistic Practice. Paris: Double Entendre.

Jenkins, Henry (2001). 'Convergence? I Diverge', Technololy Review June, p. 93.

Kozloff, S. (1995). Audiobooks in a visual culture. Journal of American Culture, 18(4), pp 83-95.

Krotz, Friedrich (2007). Mediatisierung: Fallstudien zum Wandel von Kommunikation: Wiesbaden: VS Verlag für Socialwissenschaften.

Larsen, B.S. (1999). Radio as Ritual: An Approach to Everyday Use of Radio. Nordicom Review, 21(2), 259-275.

Livingstone, Sonia (2009). Foreword: Coming to Terms with 'Mediatization'. Lundby, Knut (ed.), Mediatization: concept, changes, consequences. New York: Peter Lang Publishing.

Ludes, Peter (2008). Convergence and Fragmentation. Media Technology and the Information Society, Bristol, Chicago: Intellect.

Lundby, Knut (2009). Introduction: 'Mediatization' as Key. Lundby, Knut (ed.), Mediatization: concept, changes, consequences. New York: Peter Lang Publishing.

Meyrowitz, Joshua (1985). No Sense of Place. The Impact of Electronic Media on Social Behavior. Oxford: Oxford University Press.

Meyrowitz, Joshua (1994). Medium Theory, Crowler \& Mitchell (Eds.), Communication Theory Today. Cambridge: Polity Press.

McLuhan, Marshall (2006 [1964]). Understanding Media, London and New York: Routledge.

McLuhan, Marshall (2006), Visual and Acoustic Space. Cox C. \& Warner, D. (ed.) Audioculture, New York, London: Continuum. 
Neumark, Norie; Gibson, Ross and Leeuwen, Theo v. (Eds.) (2010). VOICE - Vocal Aesthetics in Digital Arts and Media, Massachusetts, London: The MIT Press.

Nielsen, Michael (2012). Lydbøger hitter - også i førerhuset. Retrieved 2 July 2012 from http://www.dr.dk/ Nyheder/Kultur/2012/04/132418.htm.

Norman, Donald A. (1988): The Design of Everyday Things. New York, Doubleday.

Ong, Walther J. (1982). Orality and Literacy. The Technologizing of the Word. London, New York: Methuen. Pedersen, Birgitte S. \& Have, Iben (2012). Conceptualising the audiobook experience. SoundEffects. Interdisciplinary Journal of Sound and Sound Experience, Vol. 2 no 2.

Rubery, M. (Ed.). (2011). Audiobooks, Literature, and Sound Studies. New York and London: Routledge.

Schulz, Winfried (2004). Reconstructing mediatization as an Analytical Concept. European Journal of Communication 2004 19: 87, SAGE, pp. 87-101.

Sterne, Jonathan (2006). The MP3 as cultural artifact. New Media \& Society 8(5), p 825-842.

Thompson, John B. (2010). Merchants of Culture. The Publishing Business in the Twenty-First Century. Cambridge: Polity Press.

Wingreen, Lasse (2012). Udbredelse og brug af e-lydbogen i Danmark, unpublished thesis, Department of Aesthetics and Communication, Aarhus University.

Zwoch, Maike Albertsen (2013). Interview conducted by the authors, recorded on a dictaphone, February 5, 2013.

Iben Have

Associate Professor, PhD

Media Science

Department of Aesthetics and Communication

Aarhus University, Denmark

Birgitte Stougaard Pedersen

Associate Professor, PhD

Aesthetics and Culture

Department of Aesthetics and Communication

Aarhus University, Denmark 